\title{
ERRATUM
}

\section{Erratum to: Gemcitabine Associated Pseudocellulitis}

\author{
Abhijai Singh, MD and Hemanth Hampole, MD \\ Department of Internal Medicine, John H Stroger Jr Hospital of Cook county, Chicago, IL, USA. \\ J Gen Intern Med 28(4):600 \\ DOI: $10.1007 / \mathrm{s} 11606-013-2348-\mathrm{x}$ \\ (c) Society of General Internal Medicine 2013
}

\section{Erratum to: J Gen Intern Med \\ DOI 10.1007/s11606-012-2101-x}

I

the print version of the issue in which the original article appears (J Gen Intern Med 27:1721, December 2012), the figure was reproduced in black and white, when a color representation was intended. The color version appears below for the benefit of our print readers. The publisher regrets the error.

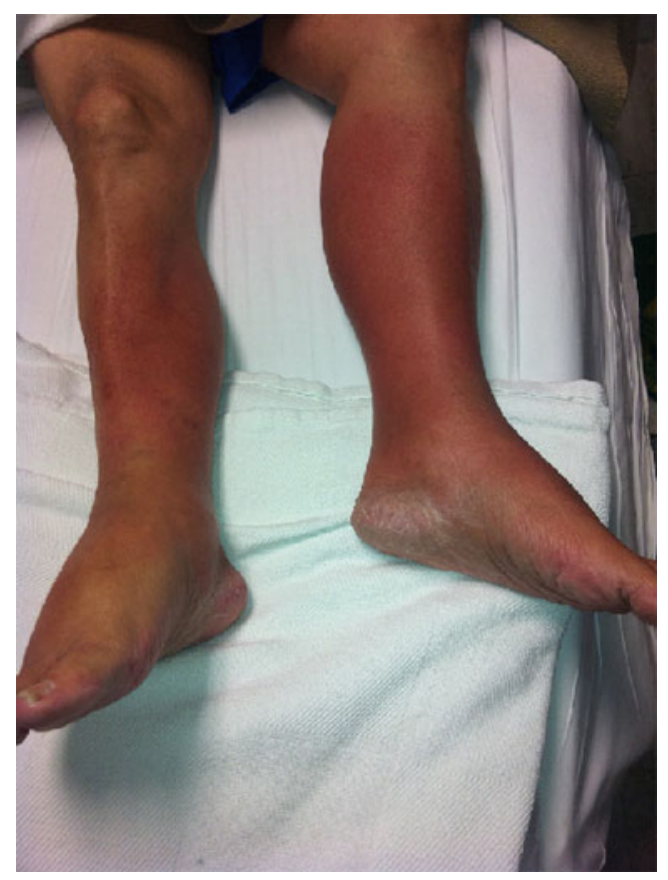

Figure 1. Elderly male patient with confluent, macular erythema on bilateral lower extremities with grade III lower extremity edema.

Corresponding Author: Abhijai Singh, MD; Department of Internal Medicine, John H Stroger Jr Hospital of Cook county, 1901, W Harrison Street, Chicago, IL 60612, USA (e-mail: abhijaisingh@gmail.com).

The online version of the original article can be found at http:// dx.doi.org/10.1007/s11606-012-2101-x.

Published online January 25, 2013 